\title{
A Conversation with Cornelius Holtorf
}

Cornelius Holtorf holds a UNESCO Chair on Heritage Futures at Linnaeus University. He read prehistoric archaeology, social anthropology and physical anthropology in Germany, England and W ales. In 1998 he gained his PbD and was subsequently employed in research and teaching at the University of Gothenburg (1998-1999), the University of Cambridge (1999-2002), the Swedish National Heritage Board in Stockholm (2002-2004) and the University of Lund (2005-2008). Since 2008 Cornelius have been working at Kalmar where he is currently a Professor of Archaeology at Linnaeus University and Director of the Graduate School in Contract Archaeology (GRASCA).

Alessandro Pintucci: Over the years you poured much energy in studying the complex relationship between archaeology and the public, particularly how popular media - thus by extension society - portray archaeologists. Looking back at 2007, when Archaeology is a Brand was first published, would you say that either society or archaeologists changed their view of our profession?

Cornelius Holtorf: Thank you for having me Alessandro and good question, it is probably time to revisit this issue! Although I have obviously not done the same amount of research on the matter since then, what I gather from both the media and the public domain in general is that what I described in the book does not seem to be hugely different from the current situation.

There certainly are many more examples today of how archaeologists are perceived and portrayed in popular culture as opposed to the early 2000s, however, some of the major themes highlighted in the book, in particular the identification of archaeologists with detectives or adventurers, are still strongly present in several different contexts. Conversely, other key features - such as the archaeologist as the person in charge of managing and rescuing sites and finds or the one able to make profound revelations about the past - are still circulating but they are also of a lesser significance than the first two aspects.

At any rate, to take stock of the current perception of the role of archaeologists in contemporary society we need to first acknowledge that the debate around heritage is changing dramatically and has been over the last few decades. The politics revolving around the identity discourse have become ever more important. How heritage represents different groups and who has control over heritage items are central factors to any political, cultural and social discourse: in this sense, the ways in which our profession is represented and thus legitimized by society is an issue that calls for our undivided attention. 
Alessandro Pintucci: Closely related to the relationship between popular culture and archaeology is the challenging connection between archaeology and pseudoarchaeology, a topic on which you take a markedly unpopular stance. In your opinion so called pseudoarchaeologists are keener on drawing people's attention to the past than actual archaeologists. If we really want to stand a chance, we should challenge pseudoarchaeologists to a contest of public engagement. Do you think that for archaeology and archaeologists to be acknowledged by the public, they should improve their social and communication game? If so, how?

Cornelius Holtorf: There are many different issues embedded in this question and probably I would start by challenging your use of the term "pseudoarchaeologists" for it entails that you already have a particular position as to who the real archaeologist is and who is the imitator.

To resist any preconceptions, I suggested to use "alternative archaeologists" as a substitute and that was well before the infamous expression "alternative facts" became popular. We certainly operate according to different standards, but instead of embarking on a crusade against alternative archaeologists, like many colleagues do, I think the real challenge is to understand what they are doing and most importantly why. In this way not only we can learn what archaeology means to them, but also what archaeology means to society. As you said, alternative archaeologists meet often with a very favourable response from the media and the public, which shows an amazing appetite for the kind of stories they bring forward. This is a fundamental factor for understanding what archaeology is actually about.

I must admit I have long thought that those who least understand what archaeology is, are archaeologists themselves. They believe our discipline revolves around studying chronologies, artifacts, and different cultures, and certainly there is some truth in that, however, this is not what resonates with the public at large. Such a narrow view of our discipline puts us at risk to lose sight of the bigger picture, i.e. how our society deals with archaeology and what role and place archaeology has. Alternative archaeology is one of the fields where I think the bigger picture becomes clearer and we can gather a better understanding on the ways professional archaeologists should act within society. If I may add, I do not consider professional and alternative archaeologists as competitors, us against them: we are in the same business, we need each other more than we can do without each other.

Ultimately most alternative archaeologists aspire to recognition. Every professional archaeologist probably happened to be emailing or calling or meeting with somebody who just wanted to be acknowledged for their work in the archaeological realm, even though the ideas conveyed are often bizarre and certainly not academic. I see here a deep desire to be appreciated which is inherent in human nature. By adding the human dimension to the equation, we stop being competitors and become colleagues, obviously not working according to the same protocols, nor publishing in the same journals or other outputs, yet in the same domain and in the same society.

In addition, I think the aim of archaeology is not necessarily to communicate to the rest of the world what we are doing, how capable we are, and what the common understanding should be of the achievements the practice of archaeology has reached over the years. We 
should focus primarily on what I call applied archaeology, on what archaeology does in society.

Applied archaeology has a number of important functions: a chief example today being tourism, which clearly is an important component of local businesses and enterprises, but also an opportunity to learn how past communities lived in our territory yet under very different circumstances. It is an opportunity to meet other tourists too, to connect people from different countries, with different stories, experiences, and interests.

If one looks at archaeology as a process, constantly evolving with and within society, then one might find that the line of demarcation between professional and alternative archaeologists is often very thin and a number of them have probably been on both sides of the fence at different times. We provide similar services to the community, so instead of emphasizing our differences we should focus on what we share, which is so much. We express ourselves through different channels, we have access to different methodologies, and we have different skills. Yet such diversity is not the most significant part in this relationship. This is why I advocate a relativization of alternative archaeology that should be considered in relation to what its proponents do and who they are and how much they share with us as professional archaeologists.

Alessandro Pintucci: Coming to your experience at the Graduate School of Contract Archaeology (GRASCA), could you briefly illustrate us the main scope of this venture and how does it interact with Swedish commercial archaeology?

Cornelius Holtorf: GRASCA is quite a unique venture - in fact I am not aware of any comparable examples within or outside Europe - and it was drafted in very specific circumstances in Sweden seven years ago now, when we first established the research school.

GRASCA stems from the collaboration between five companies in contract archaeology, Linnaeus University, and The Knowledge Foundation based in Sweden, which supports industrial research schools that aim at increased competitiveness among Swedish enterprises. Many countries have such forms of state funding, for much attention is given to enhance industry's productivity and competitiveness in the current market economy. This is an area where humanities have not much to gain, because normally we do not work under the same circumstances as those governing the industrial realm. Archaeologists fill a different function in society and more importantly there seem to be no big companies in our field. The Knowledge Foundation, however, involves all disciplines and does not limit its scope to technology, business studies or informatics: they want to spread their resources, and supporting archaeological enterprises perfectly fits within their aim.

Once it became clear that our discipline could be eligible for such a financing platform, we figured that archaeology does work competitively on a market, and it does so across many countries in Europe, especially following the Valletta Convention and the official formalization of commercial archaeology.

Contract archaeology is now a reality, and in Sweden is worth about 30 million Euros per year. The income from the commercial sector must be greater in Italy as it is a much bigger country: Sweden features 11 million inhabitants, yet building developers are working 
incessantly and, as everywhere, their projects must include preventive archaeology. Within the financing scheme promoted by the Knowledge Foundation, archaeology is eligible because it operates on a market where companies compete for contracts like in any other field. Our research school thus qualified for this fund that covered about $40 \%$ of the entire budget. This injection of money has been pivotal, otherwise there would not have been the resources for a graduate school as $\mathrm{PhD}$ students in Sweden are considered employees, they get a full salary and relevant benefits, thus they are expensive. In fact, we archaeologists at Linnaeus University do not currently have any other PhD students than those enrolled at GRASCA.

Funding aside, there is another precondition that allowed us to join forces with the commercial companies included in this venture. Swedish contract archaeology is obliged not just to take care of the finds and rescue any evidence on site, part of their remit involves also to do research and to publish the results in the regular academic venues, which I know is not often the case elsewhere in Europe where the legal and administrative frameworks are designed differently. In this sense, Swedish contract archaeologists do not require any additional training on how to do research as they are already doing it and the system works quite well.

However, the one area where GRASCA contributes to the development of contract archaeology and increases its competitiveness, is that of the relations between archaeology and society. Usually, commercial archaeologists publish their results in scientific journals, and they limit their public outreach to lectures, guided tours, exhibitions etc., now quite common undertakings in current archaeological practice. What we try to develop with our $\mathrm{PhD}$ students, is to extend the scope of the applications of archaeological knowledge to society, thus to broaden the labor market in archaeology: in fact by multiplying and diversifying the communication new customers will be created, the demand for archaeology will increase, and ultimately, we will create additional jobs in archaeology.

I should probably underline that most of Swedish archaeological companies are not in it to make profit for their owners, it is not about risk capital. These companies are often small entities, museums that have as a side contract archaeology or foundations not attached to a museum, but they work in a similar way, investing and creating new opportunities for archaeologists. Within this framework we agreed that there are certain areas where we can support their employees, some of which are now our students who do research on how to define new services to be offered that will allow to reach new markets, hence helping these companies to grow.

This is the main task of our $\mathrm{PhD}$ students, it does require a system where the standard research side is already under control, so to say: we identified the new research area in contract archaeology that needed to be expanded, testing new grounds, and which at the same time is something where our capacity and expertise at the university could contribute by providing additional knowledge and innovative approaches.

We are now six and a half years old; the first two PhDs have finished by now and there are several others lined up, which over the next few years will add up to nine in total. We seem to have every reason to hope that this venture will lead to some interesting developments in Swedish contract archaeology. The first $\mathrm{PhD}$ researcher, for example, a human osteologist, had been focusing on developing forensic archaeology in Sweden, quite a big field in the UK that started several decades ago and made huge progresses since 
then. Yet in our country it does not exist at the moment, it boils down to individual police officers with an interest in archaeology who seek for the assistance of a professional archaeologist in various circumstances, but certainly not within a structured system. Our young researcher is the person who, in joint effort with her employer - a museum in this case- is trying to turn forensic archaeology into a common, systematic practice. We will have to assess real outcome of this $\mathrm{PhD}$ research over time, but certainly the starting position is a very promising one: she is already well known in the right police circles, she has been on national television where she successfully promoted the key ideas at the core of her research.

Alessandro Pintucci: The reality you are describing in Swedish contract archaeology is strikingly different from that of Italy. Commercial companies here are indeed only focused on their preventive duties on site and their budget does not certainly allows for investing in other projects or assessing alternative ways of expending the job market in archaeology. To come back to the human dimension you mentioned above, what do you think is the factor that triggers such an approach?

Cornelius Holtorf: Well, it does require to have a particular kind of leader in these establishments, and we are lucky to collaborate with companies that have this leadership aiming at investing not only in new forms of staff development and capacity building, but also an in future projects and new markets, which makes commercial sense as well.

I have to say, however, that we would have taken in a few more $\mathrm{PhD}$ students than we actually did, if only we could have found more companies up to the task. The challenges are similar everywhere and not all businesses either want to explore new avenues or are able to do so because, again, such an approach does need financial support, and securing that is always difficult.

Alessandro Pintucci: Certainly, the role of commercial companies in archaeology is even more challenging now, after the long gap caused by the outbreak of Covid 19, that impacted dramatically the building sector. The example of GRASCA is unique yet inspiring, thank you very much Cornelius for sharing your experience there and joining us today! 
